УАK 342.5

ББK 67.400.6

DOI 10.22394/1682-2358-2018-2-20-26

T.S. Satyr, research assistant of the Expert-Analytical Center, postgraduate student of the Public Relations and Media Policy Department, Russian Presidential Academy of $\mathrm{Na}$ tional Economy and Public Administration

\section{THE EXPERT \\ MAINTENANCE \\ OF AUTHORITIES' \\ ACTIVITY \\ IN THE COURSE \\ OF MAKING PUBLIC \\ MANAGERIAL \\ DECISIONS}

The current situation of expert maintenance of authorities' activity and the role of expert community in making public managerial decisions is analyzed. It is emphasized that, despite the presence of a great number of various expert analytical centers and institutions, it is not uncommon that the issue of their practices efficiency, as well as developing ways to big up the status of the experts and expert communities is raised.

Key words and word-combinations. expert community, public administration, expert and analytical support.
T.C. Camoıрь, науиньй сотрудник Экспертно-аналитического центра, аспирант кафедриг общественньгх связей и медиаполитики Российской академии народного хозяйстьа и государственной службьг при Президенте РФ (email: tatiana_satyr@mail.ru)

\section{ЭКСПЕРТНОЕ СОПРОВОЖАЕНИЕ АЕЯТЕ $\Lambda$ ВОСТИ ОРГАНОВ ВААСТИ В ПРОЦЕССЕ ПРИНЯТИЯ ГОСУААРСТВЕННЫХ

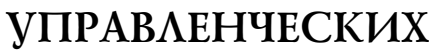 РЕШЕНИЙ}

Аннотаџия. Анализируется современная ситуация экспертного сопровождения деятельности органов власти и выявляется роль экспертного сообщества в принятии государственных управленческих решений. Обращается внимание на то, что, несмотря на наличие огромного числа экспертно-аналитических структур, нередко возникает вопрос как об эффективности их деятельности, так и направлениях повышения статуса самого эксперта и экспертного сообщества.

Ключевые слова и словосочетания: экспертное сообщество, государственное управление, экспертно-аналитическое сопровождение.

$\mathrm{H}$ периодом Аля современной российской системы государственной вАасти и управцения. Именно в это время произошел ее переход из стадии начамьного формирования к стаАии развития базовых основ и институтов. Современная социамьно-экономическая и 
политическая ситуащии в обществе быстро меняются, что способствует постоянному выдвижению новых цемей и задач перед органами государственного управления, а главное, необходимости принятия оперативных, грамотных и научно обоснованных решений. Так, органам государственной вмасти необходимо не только пересматривать и вносить коррективы в уже существующие традиционные методы управления, но и постоянно повышать эффективность своей деятельности. С этой целью при принятии управленческих решений важно опираться исключительно на достоверные данные и информацию, экспертные ощенки и мнения профимьных спещиалистов.

Актуальность данной публикаџии обусловлена необходимостью анализа экспертного сопровождения деятельности органов власти в проџессе принятия государственных управленческих решений. В связи с постоянным увеличением объема информации растет необходимость в грамотных и опытных специалистах-экспертах профильных направлений, способных качественно анамизировать поступающую информацию и содействовать выработке решений с учетом анализа современной ситуации.

Согласно Большой советской энџикмопедии «эксперт - специалист в обмасти науки, техники, искусства и других отраслей, приглашаемый Аля исследования каких-либо вопросов, решение которых требует специальных знаний» [1]. По С.И. Ожегову «эксперт - специалист, делающий заключение при рассмотрении какого-либо вопроса» [2]. Следовательно, эксперт - это специалист, чья деятельность направлена на консультирование, оџенку и выработку рекомендаџий, с использованием при этом имеющегося опыта, специальных знаний и навыков в той или иной сфере деятельности.

Согласно точке зрения директора Международного комледжа современных технологий Е.В. Казаковой, экспертное сообщество можно рассматривать в авух смыслах [3, с. 11-14]. В узком смысле экспертное сообщество - объединение Аиц, обладающих спещиальными знаниями Аля решения какой-либо задачи. Например, конкретный аналитический или исследовательский центр, институт или подраздемение. В широком смысле сообшество преАставцяет собой среАу (пространство), в которой генерируются экспертные закмючения и идеи по направлениям человеческой деятельности.

Под экспертной деятельностью в основном понимается деятельность, вкцючающая в себя управленческое консультирование, получение уникальной информации, диагностику и мониторинг, экспертное прогнозирование [4, с. 18-21]. Помимо перечисленного, следует отметить и такие направления, как подготовка аналитических материалов; экспертиза научно-исследовательских работ, программ и законопроектов, результатов исследований; участие в законотворческой деятельности; реализация научно-исследовательских работ и проектов; проведение мероприятий и публичная активность.

Экспертно-аналитические и консультационные структуры начали получать свое распространение в России с конџа 1950-х годов, с началом научно-технической револющии. Создавались и развивались партийные аналитические центры, академические исследовательские институты, отдельные центры и маборатории, автономные аналитические центры, «фабрики мысли». Исследо- 
ватели, ученые выделяют различные способы классификации экспертно-анакитических структур. Основные из них: 1) структуры и центры, образованные при органах государственной власти; 2) частные анамитические центры, деятельность которых направлена на проведение исследований, изучение мнений населения, осуществляемая на контрактной основе; 3) исследовательские аналитические џентры, явцяющиеся научной структурой, состоящей преимущественно из деятелей науки. Каждая из выделенных групп осушествляет взаимодействие с органами государственной вмасти на различных этапах и в различных формах. Так, к государственным структурам можно отнести экспертные советы при министерствах федеральных органов власти, экспертные советы при комитетах Государственной Аумы Федерального Собрания Российской Федераџии, Экспертный совет при Правительстве Российской Федерации и т.А. Аанные органы осушествцяют прямое сопровождение деятельности соответствующих структур. К частным аналитическим центрам можно отнести ВЦИОМ (Всероссийский центр изучения общественного мнения), АеваАа-центр, ФОМ (ФонА «Общественное мнение) и другие. Эти организаџии осуществмяют собственные и заказные соџиологические и маркетинговые иссмедования. Наконец, научные центры, преимушественно при вузах (НИУ ВШЭ, МГУ, РАНХиГС, Финансовый университет при Правительстве РФ, РАН и др.). Некоторые авторы выдемяют также разновидности «фабрик мысли»: академические (университеты без студентов); осушествляющие исследования по контракту; идеологизированные; партийные [5, с. 62-74]; ситуационные центры [6, с. 1-9]. Особое место в экспертной среде занимают сетевые экспертные сообшества.

ОАним из ярких примеров явмяется Аналитический центр при Правительстве Российской Федерации [7]. В его функции входят оперативное информационно-аналитическое сопровождение и экспертная поддержка деятельности Правительства Российской Федерации по основным вопросам соџиально-экономического развития страны в сферах финансов, промышменной политики, энергетики, сельского хозяйства, транспорта, энергоэффективности, охраны окружающей среды, стратегического планирования, проектного управмения, регионального развития, соџиально-трудовых отношений, образования, здравоохранения, инноваций, информационных техномогий и Аругих вопросов.

Актуальность экспертного сопровождения в настоящее время растет: преАставители органов власти нужАаются в принятии верных управленческих решений, подкрепленных мнением опытных, грамотных и глубоко погруженных в разнообразные тематические области знаний специалистов. Необходимость и значимость экспертного сопровождения деятельности органов власти поАтверждается результатами проводимых исследований, экспертными мнениями и научными публикациями российских и зарубежных авторов.

В течение достаточно Алительного времени нами проводится соџиологическое исследование среди представителей научных и исследовательских структур, органов государственной вмасти, научного и бизнес-сообшества, чменов экспертных советов, которые участвуют в экспертном сопровождении де-

22 Bulletin of the Volga Region Institute of Administration • 2018. Vol. 18. № 2 
ятельности органов власти*. Уже на данном этапе исследования можно подтвердить утверждения Аругих соџиологов и исследователей: $82 \%$ опрошенных считают, что экспертное сопровождение деятельности органов власти явцяется необходимой и важной составмяющей дмя принятия решений (рис. 1).

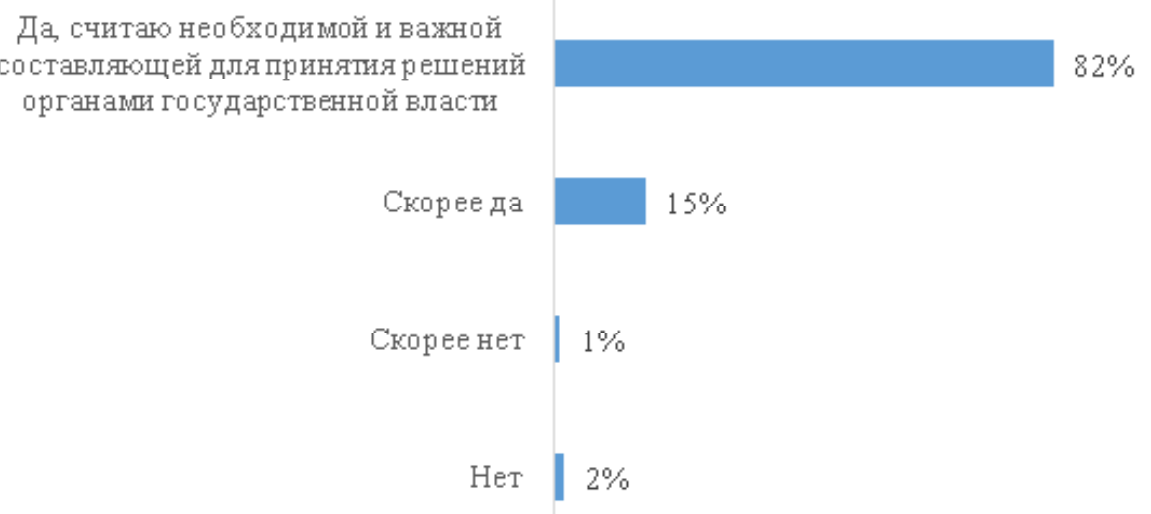

Рис. 1. Ответы на вопрос «Считаете ми вы необходимым экспертное сопровождение деятельности органов государственной вмасти?»

Актуальными вопросами в определении роли экспертного сообщества явмяется определение формата взаимодействия с органами власти и осуществмение соответствующих функщий. Все обозначенные функщии экспертных структур можно объединить в две группы: инструментальную и символическую [8, с. 8-15]. ПоА инструментальной функцией понимают такой проџесс, когАа экспертная оценка действительно интересует представителей властных структур и выступает в качестве инструмента при принятии решений. Символическая функщия экспертного сообщества проявмяется, когда деятельность и мнение экспертов не учитывается при принятии управленческих решений, явцяясь формальной. ГАавным зАесь явмяется символическое привлечение экспертов к деятельности и повышение кегитимности уже по сути принятого решения.

В связи с этим экспертам задавался вопрос «По вашему мнению, учитываются ли результаты деятельности экспертного сообщества в принимаемых органами власти решениями?» (рис. 2). 61\% экспертов отметили, что их экспертное мнение и материалы учитываются при принятии решений, но частично. Многие опрошенные (32\%) свидетельствуют об отсутствии внимания к их экспертной деятельности.

Существуют различные кмассификащии этапов принятия решений. Рассмотрим оАну из них $[9$, с. 18$]$ :

1. Выявление и формулирование проблемы.

\footnotetext{
* На 1 марта 2018 г. опрошены 170 экспертов, 63 из них являются членами экспертных советов, 107 участвуют в экспертном сопровождении в других форматах. Анкетирование проводится среди представителей научных и исследовательских структур, органов государственной власти, научного и бизнес-сообщества, членов экспертных советов. Опрос продолжается.
} 
2. Формирование группы по подготовке решений проблемы.

3. Сбор информации и анализ проблемы.

4. Подготовка и обоснование вариантов решения.

5. Выбор и принятие решения.

6. Организация исполнения решения.

7. Контроль и оџенка результатов исполнения решения.

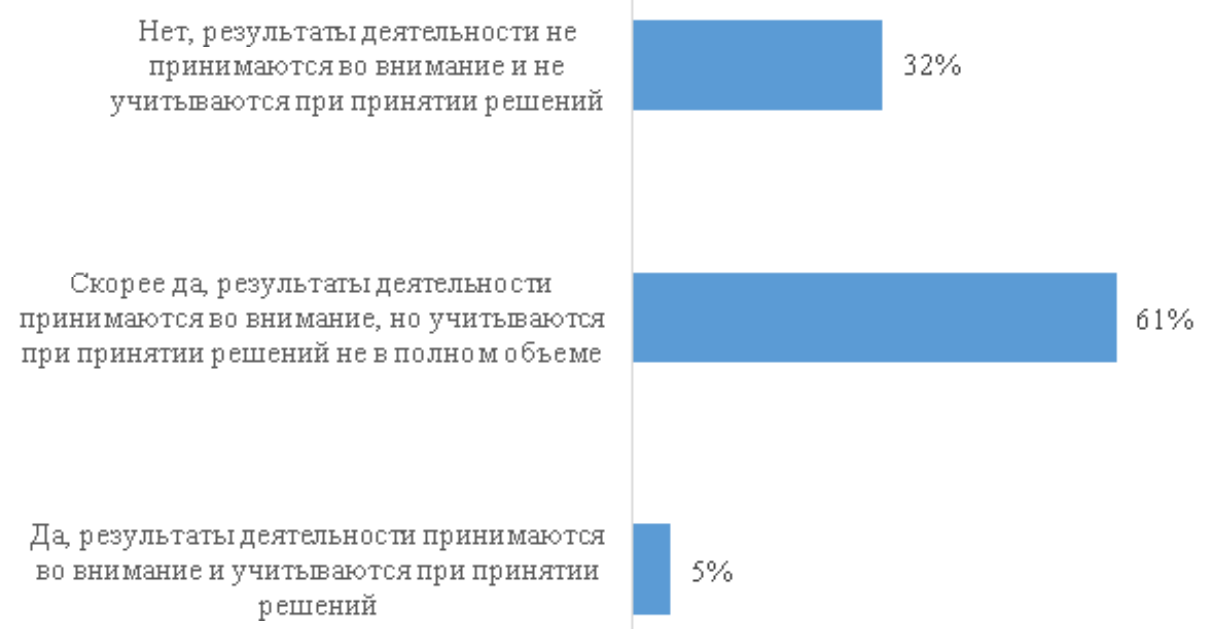

Рис. 2. Ответы на вопрос «По вашему мнению, учитываются $\Lambda и$ результаты деятельности экспертного сообщества в принимаемых органами вмасти решениях?»

В ходе проводимого исследования некоторые этапы были обобщены, а некоторые, наоборот, более конкретизированы дмя кучшего понимания респондентами. Так, по мнению экспертов, экспертно-аналитическое сопровождение деятельности необходимо на всех этапах процесса принятия решений органами власти $(28 \%)$. Большой процент опрошенных подтверждают важность работы экспертов на этапе экспертизы и оџенки документа (25\%), а также цемесообразность вкмючения в работу на начальном этапе разработки документа (23\%) (рис. 3).

Как видим, существует огромное количество как государственных, так и частных аналитических структур, деятельность которых направлена на экспертное сопровождение и повышение качества принимаемых управленческих решений. ОАнако практика показывает, что не всегда наличие самой структуры гарантирует повышение качества принимаемых решений. При этом экспертное сообшество не всегда востребовано и не всегда готово эффективно реализовывать свои функции. Возникают вопросы и к эффективности деятельности создаваемых экспертных структур, и к повышению статуса самого эксперта и экспертного сообщества. Ведь именно от уровня квалификации, наличия необходимых компетенций, опыта работы эксперта (не только по временному периоду, но и по количеству качественно подготовленных и реализованных проектов, работ, материалов) зависит качество предоставцяемого материала и значимых оценок и прогнозов.

24 Bulletin of the Volga Region Institute of Administration • 2018. Vol. 18. № 2 


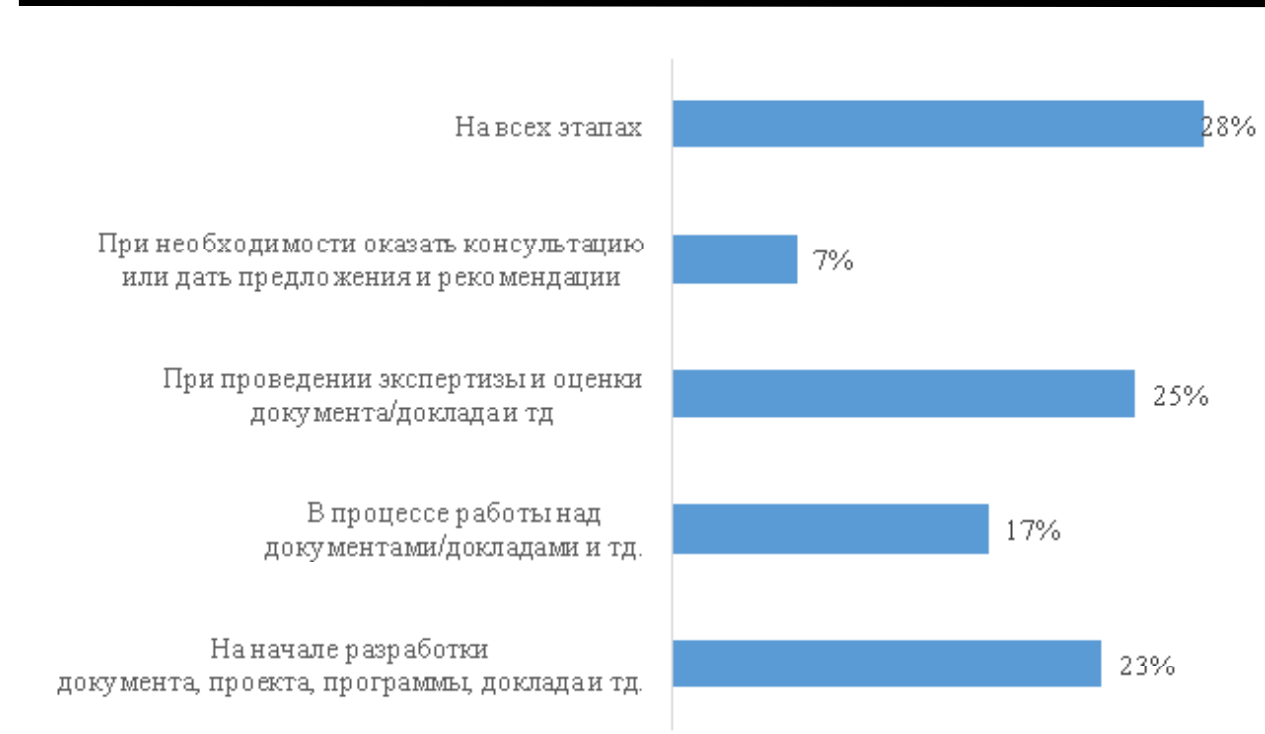

Рис. 3. Ответы на вопрос «Как вы считаете, на каком этапе процесса принятия решений экспертно-аналитическое сопровождение играет наибольшую роль?»

Сегодня отмечаются следующие проблемы, с которыми сталкиваются как органы власти, так и экспертное сообщество в проџессе экспертно-аналитического сопровождения деятельности:

1) не используется или нерационально используется при сложившейся структуре экспертный потенџиал и (или) экспертный ресурс [10, с. 82-83];

2) отсутствует консолидирующее ядро экспертного сообщества, наблюдается доминирование закрытых, корпоративных экспертных групп, тесно аффилированных с властными структурами [11, с. 171-173]. В. Римский отмечает, что в результате практически весь опыт экспертов связан с исслеАованиями, уже согласованными с государственными приоритетами, поэтому Ааже при наличии разнообразия мнений и оџенок российское экспертное сообщество наиболее эффективно отстаивает приоритеты и интересы госуАарства, а не гражАан [12, с. 42$]$;

3) отмечается недостаток механизмов транслирования экспертных знаний и семекции перспективных идей;

4) существует необходимость в совершенствовании нормативно-правовой базы об экспертной деятемьности;

5) отсутствуют четкие критерии оџенки эффективности экспертно-анамитического сопровождения решений и критерии статуса «эксперт» $[13$, c. 64-69];

6) нет достаточной прозрачности и открытости результатов экспертной деятельности. Проведенный автором анализ информации, находящейся на информационных ресурсах, о деятельности экспертных советов министерств Российской Федераџии позволяет сделать вывоА об отсутствии в открытом 
доступе полной информаџии о деятельности экспертных советов и их составе, заседаниях, что затрудняет возможность внешним экспертам и заинтересованным Аицам проводить собственный анализ реализации принятых решений на заседаниях, а также знакомиться с составом экспертов Аля подтверждения качества предоставляемых материалов.

Безусловно, Аля повышения эффективности деятельности органов власти необходима четко выстроенная система экспертно-аналитического сопровождения с отобранными высококвалифицированными экспертами и направленная на подготовку качественных материалов и программ, выработку преАможкений и построение прогнозов с целью их последующей реализации, что подразумевает повышение внимания к обозначенной проблеме.

\section{Библиографический список}

1. Большая советская энциклопедия, 1969-1978. URL: http://enc-dic.com/enc_sovet/Jekspert102389.html

2. Толковый словарь Ожегова, 1952. URL: http://slovarozhegova.ru/word.php?wordid=36169

3. Казакова Е.В. Роль экспертных сообществ в политической модернизации // Власть. 2011. № 3. C. 11-14.

4. Майкевич Н.В, Травина Л.Л. Доклад «Организационно-технические требования к формированию и развертыванию экспертно-аналитической сети, обеспечивающей информационно-аналитическое сопровождение программно-проектной деятельности органов государственной власти» / Федеральное государственное учреждение «Аналитический центр при Правительстве Российской Федерации». М., 2009. С. 18-21.

5. Горный М.Б. Фабрики мысли и центры публичной политики в конце XX - начале XXI века // Публичная политика. СПб., 2006. С. 62-74.

6. Райков А.Н. Новая парадигма развития ситуационных центров // Системный анализ в науке и образовании: электронный журнал. 2010. № 1. С. 1-9.

7. Аналитический центр при Правительстве Российской Федерации. URL: http://ac.gov. $\mathrm{ru} / \mathrm{about} /$

8. Сунгуров А.Ю. Роль и функции экспертов в процессе принятия властных решений // Управленческое консультирование. 2017. № 6. URL: https://sziu.ranepa.ru/images/nauka/UK DOI/6 17/Sungurov 6 17.pdf

9. Ж. Жиарь О.В. Разработка управленческого решения в органах государственной власти и местного самоуправления: учебное пособие. Челябинск, 2008.

10. Грабельных Т.И. Экспертное сообщество и экспертные практики в России: методология исследования проблем развития: тезисы докладов IV Всероссийского социологического конгресса. М., 2012. С. 82-83. URL: http://www.isras.ru/VSK_IV_partion. html? section $=2$

11. Сосунов Д.В. Роль экспертного сообщества в процессе принятия политических решений // Вестник ВГУ. Сер.: История. Политология. Социология. 2012. № 1. С. 171-173. URL: http://www.vestnik.vsu.ru/pdf/history/2012/01/2012-01-33.pdf

12. Римский В.Л. Роль экспертного сообщества в российской публичной политике // Городское управление. 2006. № 5.

13. Райков А.Н. Сетевая экспертная деятельность: препятствия и стимулы // Государственная служба. 2010. № 4. С. 64-69. 